\title{
Cinétiques des activités amylolytique et protéolytique de deux bactéries du rumen
}

\author{
A Marchand, C Héritier-Frèche, G Blanchart \\ INRA-ENSAIA, laboratoire de zootechnie, \\ 2, avenue de la Forêt de Haye, 54500 Vandceuvre-lès-Nancy, France
}

\begin{abstract}
Summary - Kinetics of amylolytic and proteolytic activities of 2 rumen bacteria. Proteolytic and amylolytic activities of $S$ bovis and $B$ ruminicola were studied using wheat or maize meal as substrate. With $S$ bovis both activities started at the beginning of bacterial growth, whereas with $B$ ruminicola, proteolysis started 48 or $72 \mathrm{~h}$ later.
\end{abstract}

Les cinétiques des activités amylolytique et protéolytique ont déjà été étudiées, de façon indépendante, chez différentes espèces bactériennes du rumen. En revanche, peu d'études sont consacrées à l'observation et à l'interprétation de ces activités mixtes lorsqu'elles sont présentes chez une même bactérie.

Matériel et méthodes - Deux espèces bactériennes amylolytiques et protéolytiques, Streptococcus bovis et Bacteriodes ruminicola, ont été isolées du rumen de moutons fistulés recevant un régime constitué de luzerne déshydratée, de blé concassé et de foin. Elles sont cultivées sur le milieu décrit par Russel et al (1981) enrichi avec environ $10 \%$ de farine de blé ou de maïs. La concentration initiale en protéines varie en fonction de la nature et de la concentration de la céréale. Le dosage des protéines résiduelles (par colorimétrie au bleu de Coomassie) et la mesure des activités amylasique (par mesure de l'hydrolyse de l'amidon bleu azur) et protéasique (par mesure de l'hydrolyse de l'azocaséine) montrent l'évolution sur $5 \mathrm{j}$, des activités hydrolytiques et de leurs interactions chez ces 2 bactéries.

Résultats et discussion - Avec $S$ bovis (fig 1), les protéines de maïs sont plus rapidement dégradées que celles de blé; pour les 2 aliments, cette dégradation est incomplète $(\approx 66 \%)$. L'activité protéasique s'élève rapidement, en liaison probable avec l'accroissement exponentiel du nombre de cellules. Cette observation fait penser à une libération notable des protéases dans le milieu. Par la suite, l'activité protéasique diminue alors que la teneur en protéines se stabilise.

L'activité amylasique est au maximum à $24 \mathrm{~h}$, et disparaît après $48 \mathrm{~h}$. Les amylases, dont la production est induite par l'amidon, sont probablement réprimées par des métabolites de l'amylolyse tels que le glucose (Cotta, 1988).

En l'absence de bactéries utilisant les différents métabolites, la croissance et les activités amylolytique et protéolytique de $S$ bovis sont ralenties (Cotta, 1988).

Avec $B$ ruminicola, la dégradation des protéines est aussi incomplète. Elle débute très lentement dès le $1^{\text {er }}$ jour avec le blé, mais seulement après le $3^{e}$ jour avec le maïs. L'activité protéasique ne se développe qu'en phase stationnaire, après la phase de croissance exponentielle (Hazlewood et Edwards, 
Streptococaus bovis + Farine de Ble

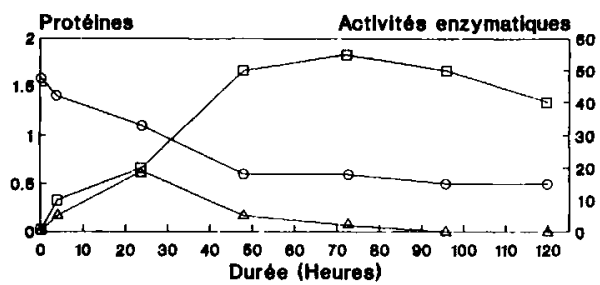

Streotecoccus bovis + Farine de maïs

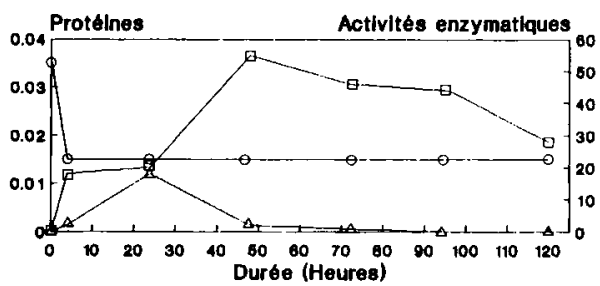

Bacterordes ruminicola + Farine de ble

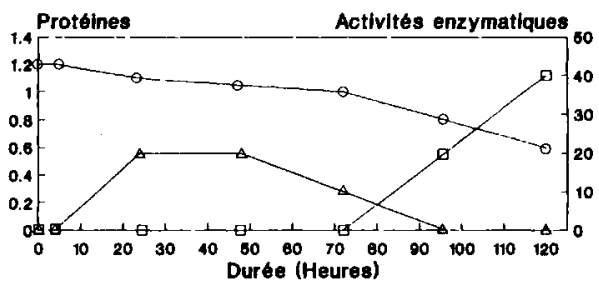

Bacteroudes ruminicola + Farine de maïs

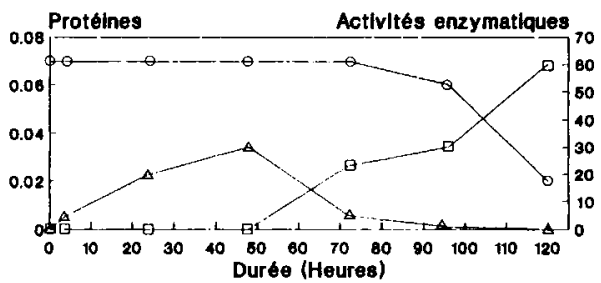

Fig 1. Évolution des concentrations en protéines $(O \mathrm{en} \mathrm{mg} / \mathrm{ml}$ ) et des activités amylasique $(\triangle$ en UE/ml) et protéasique $(\square$ en $\mathrm{ng} / \mathrm{ml}$ ) dans des cultures pures de $S$ bovis et de $B$ ruminicola en présence de farine de blé ou de maïs (5 répétitions).

1981), soit après le début de la lyse cellulaire. Les protéases sont donc probablement en grande partie attachées aux cellules bactériennes.

Comme dans le cas de $S$ bovis, l'activité amylasique se manifeste dès le début de la multiplication cellulaire. Cependant, chez $B$ ruminicola, elle disparaît plus tardivement.

Deux hypothèses peuvent être émises pour expliquer les différences de cumportement entre les 2 bactéries:

- chez $S$ bovis, la production d'amylase ne modifie pas celle des protéases. Au contraire, chez $B$ ruminicola, l'activité protéasique ne se développe qu'à partir du moment où la production d'amylase diminue;

- il est également possible de considérer que $B$ ruminicola doit, pour exprimer son activité protéolytique, trouver dans le milieu de fermentation des substrats carbonés simples que lui fournirait l'amylolyse. Ce mécanisme caractériserait une différence d'exigence nutritionnelle entre les 2 bactéries.

En conclusion, l'interaction entre les activités protéolytique et amylolytique dépend de l'espèce bactérienne, et est probablement déterminée par les caractéristiques des enzymes : structure, localisation et régulation.

Cotta MA (1988) Appl Environ Microbiol 54, $772-776$

Hazlewood GP, Edwards R (1981) J Gen Microbiol 125, 11-15

Russel JB, Bottje WG, Cotta MA (1981) $J$ Anim Sci 53, 242-252 